\title{
Feasibility study of the immunogenicity and safety of a novel DTPw/Hib (PRP-T) Brazilian combination compared to a licensed vaccine in healthy children at 2,4 , and 6 months of age
}

\author{
Estudo de viabilidade de imunogenicidade e segurança de uma nova vacina \\ brasileira combinada DTPw/Hib (PRP-T), comparada com uma \\ vacina registrada, em crianças de 2, 4 e 6 meses de idade
}

\section{SueAnn Costa Clemens ${ }^{1}$ Tania Azevedo ${ }^{2}$ and Akira Homma ${ }^{3}$}

\begin{abstract}
Vaccination of infants with conjugated Haemophilus influenzae type $b$ (Hib) vaccines has been proven to reduce Hib meningitis by $95 \%$ and pneumoniae by $20 \%$. The routine use of Hib vaccine is facilitated by the introduction of combination vaccines into the EPI (Expanded Plan of Immunization). The objective of this study was to compare the immunogenicity and reactogenicity of an extemporaneously mixed DTPw/Hib (diphtheriatetanus-whole cell pertussis) combination, using the technology of two Brazilian manufacturers, against a licensed DTPw/Hib European combination in 108 infants vaccinated at 2, 4 and 6 months according to the local national schedule. The Brazilian combination was highly immunogenic with Hib seroprotection rates (anti-PRP $>0.15 \mathrm{mg}$ $/ \mathrm{ml}$ of $98 \%$ after 2 doses and $100 \%$ after 3). Also for tetanus and pertussis the new Brazilian combination was as immunogenic as the European counterpart, except the diphtheria seroprotection rates and titers were lower. There was also no clinically relevant difference in reactogenicity. If these feasibility results are confirmed, the Brazilian DTPw/Hib combination should help to boost the uptake of Hib vaccination in Brazil.
\end{abstract}

Key-words: Combination vaccines. DTPw/Hib. Brazilian vaccines technology transfer.

Resumo A vacinação contra (Haemophilus influenzae) tipo b (Hib), utilizando vacinas conjugadas, provou reduzir em $95 \%$ os casos de meningite e em $20 \%$ as pneumonias por Hib. O uso rotineiro da vacina Hib foi facilitado pela introdução das vacinas combinadas no Programa Ampliado de Imunização (PAI). O objetivo deste estudo foi comparar a imunogenicidade e reatogenicidade da mistura extemporânea da vacina combinada contra difteria-tétano-pertussis de células inteiras/Haemophilus influenzae (DTPw/Hib), de tecnologia e produção de 2 fabricantes brasileiros, à vacina européia registrada DTPw/Hib. Estudo realizado em 108 crianças em idade de 2, 4 e 6 meses, seguindo o esquema nacional de imunização. A vacina combinada brasileira foi altamente imunogênica, apresentando taxas de soroproteção anti-Hib (anti-PRP $>0.15 \mathrm{mg} / \mathrm{ml}$ de $98 \%$ após 2 doses e 100\% após 3 doses). A vacina combinada nacional foi tão imunogênica quanto a européia para tétano e coqueluche. As taxas de soroproteção e títulos geométricos do componente diftérico foram menores em relação à combinação européia. No tocante a reatogenicidade não houve diferença clínica relevante. Se estes resultados de viabilidade da nova vacina combinada brasileira DTPw/Hib forem confirmados, este novo avanço tecnológico ajudará a manter e melhorar os ótimos níveis de cobertura vacinal (anti-Hib) alcançados no Brasil.

Palavras-chaves: Vacinas combinadas. DTPw/Hib. Transferência de tecnologia das vacinas brasileiras.

\footnotetext{
1. Instituto Carlos Chagas, Rio de Janeiro, RJ. 2. Universidade Federal do Rio de Janeiro, Rio de Janeiro, RJ. 3. Bio-Manguinhos da Fundação Oswaldo Cruz, Rio de Janeiro, RJ.

The research was supported by a restricted grant of Glaxo SmithKline.

Address to: Dra. SueAnn Costa Clemens. Glaxo SmithKline do Brasil, Estrada dos Bandeirantes 8464, 22783-110 Rio de Janeiro, RJ Brasil. Tel: 5521 2444-6095

Recebido para publicação em 14/3/2002

Aceito em 2/4/2003
} 
Haemophilus influenzae type b (Hib) has been the leading cause of bacterial meningitis in many parts of the world before the introduction of vaccination against $\mathrm{Hib}$. In Latin America, the incidence of Hib meningitis in children aged 0 to 4 years is 35 per 100,000, and the incidence of any Hib disease is 60 per $100,000^{34}$. In Brazil Hib accounts for about one third of childhood bacterial meningitis ${ }^{72}$. The peak incidence of disease in Brazil is during the first year of life with many cases occurring as early as 0-6 months of age ${ }^{22}$.

It has been shown that antibodies to the capsule of $H$. influenzae type b polyribosylribitol phosphate (PRP) have biological activities against the organism ${ }^{47}$ and are effective in both the treatment and prevention of disease $e^{36} 40$. A capsular polysaccharide vaccine was developed in the mid 80's, but was poorly immunogenic in children less than 15 months of age $e^{43}$. Therefore, in an attempt to enhance the immunogenicity of this T-cell independent antigen, several PRP conjugate vaccines have been developed that covalently link PRP to a protein carrier, such as tetanus-toxoid $(T)^{46}$. These Hibconjugate vaccines have been shown to prime for memory responses ${ }^{19}$ in addition to being immunogenic in the very young. They have proven to be highly effective, with protection rates against Hib meningitis well above $95 \%{ }^{8} 35$ and of over $20 \%$ against radiologically confirmed pneumonia.

Because of this extraordinary efficacy and effectiveness, World Health Organization (WHO) recommended in 1998 that Hib vaccination should be included in routine infant immunization programs ${ }^{49}$, preferably together with DTP (diphtheria/tetanus/pertussis). Since its introduction in
1957 DTP vaccine has gained high acceptance with a target of a $90 \%$ worldwide coverage by $2000^{37} 48$. In Brazil, the coverage in the last years has already surpassed this level. Because both vaccines are given as a 3-dose schedule at the same age and a combination was technically feasible, DTPw/PRP combination vaccines were rapidly developed. Such new combinations would use the high acceptance of DTPw to facilitate the introduction of $\mathrm{Hib}$, to reduce the number of injections, to increase compliance, and to reduce program costs.

Several studies have addressed the safety and immunogenicity of those DTPw-Hib combinations versus the separate administration of the two vaccines.

Although some studies have shown modest and clinically irrelevant reductions in antibody titers to PRP, tetanus or pertussis ${ }^{131718}$, most have found no evidence for reduced immunogenicity ${ }^{1} 42839$, even in a stringent accelerated immunisation schedule as used in the $\mathrm{UK}^{3}$. Furthermore, the combination of PRP with DTPw did not increase the rate of local or systemic reactions ${ }^{1361318253039}$.

However, each new DTPw/Hib combination has to be tested again for lack of interference both for safety and immune responses ${ }^{33}$. Brazil is one of the few developing countries with an efficient public vaccine industry. Recently, Bio-Manguinhos has acquired the technology from GSK Biologicals to produce Hib vaccine locally in Brazil. The aim of this study was to show that it is feasible to mix extemporaneously the Hib conjugate (PRP-T) vaccine produced with the GSK Biologicals /Bio-Manguinhos Fundação Oswaldo Cruz (FIOCRUZ) technology with a locally manufactured DTPw from Instituto Butantan.

\section{MATERIAL AND METHODS}

The study was designed as a phase III observerblind, prospective, randomized, controlled trial in a single vaccination center and was conducted according to the Declaration of Helsinki and to Brazilian and European Good Clinical Practice guidelines.

Subjects. Healthy infants of either gender between 6 and 14 weeks of age were recruited. The protocol, including parent information sheet, was approved by the Ethics Committee of the principal investigator's affiliation and country health authorities, prior to study start. Written informed consent was obtained from the parents/ legal guardians of each child before subject enrollment.

Exclusion criteria were: prematurity, acute moderate to severe disease, immunodeficient conditions or acute immunosuppressive therapy, neurological disorders or previous seizures, and previous allergic reactions. All infants were recruited in one study center in a rural part of Rio de Janeiro State. The population consisted of children from low to medium socioeconomic class families without overcrowding.

Vaccines. DTPw Instituto Butantan: each $0.5 \mathrm{ml}$ dose of the vaccine manufactured by Instituto Butantan, São Paulo, Brazil, contained purified diphtheria toxoid (10 Lf), purified tetanus toxoid (10 Lf), and inactivated Bordetella pertussis whole cell suspension (16 OU) as well as aluminum hydroxide $(<1.25 \mathrm{mg})$ and thiomersal as preservative.

DTPw GlaxoSmithKline Biologicals: each $0.5 \mathrm{ml}$ dose of the vaccine manufactured by GlaxoSmithKline Biologicas, Rixensart, Belgium, contained purified diphtheria toxoid (>30 IU), purified tetanus toxoid (> 60 $\mathrm{IU})$, and inactivated Bordetella pertussis whole cell suspension ( $>2 \mathrm{IU}$ ), as well as $0.4 \mathrm{ml}$ aluminum salt and 2-phenoxy ethanol as preservative.

PRP-T: PRP-T was manufactured by GSK Biologicals, Belgium, using the same technology as transferred to Bio-Manguinhos - FIOCRUZ, Rio de Janeiro in 1998. Two slightly different but bioequivalent formulations were prepared for this study. The vaccines were composed of $10 \mathrm{mg}$ Haemophilus influenzae type b capsular polysaccharide (PRP) and conjugated to 20$40 \mu \mathrm{g}$ tetanus toxoid as protein carrier. They were presented as a freeze-dried pellet in a monodose vial to be reconstituted with liquid DTPw.

$D T P$ W/PRP-T combination: a single dose of the DTPw/PRP-T combination was prepared by resuspending 
one vial of the freeze-dried PRP-T vaccines with the content of one vial of DTPw manufactured by Instituto Butantan (group 1), or one vial of DTPw from GSK Biologicals (group 2).

All vaccines used in this trial were released according to the manufacturers Quality Control (QC) criteria and approved by Instituto Nacional de Controle de Qualidade em Saúde (INCQS).

Study design and objectives. Infants were randomly allocated to one of the two study groups, using an algorithm of pseudo random numbers (RS/1, BBN Inc.). Infants allocated to study group 1 received PRP-T reconstituted with DTPw from Instituto Butantan, those of group 2 got PRP-T reconstituted with DTPw from GlaxoSmithKline Biologicals. The vaccines were administered by deep intramuscular injection into the left anterolateral thigh at 2, 4 and 6 months of age. All children of both groups were to receive OPV at 2, 4 and 6 months as well as their third dose of hepatitis B (Engerix-B ${ }^{\mathrm{TM}}$ GSK Biologicals) at 6 months of age.

If after vaccine administration one of the following adverse events occurred - fever $>40.5$ Co, persistent inconsolable crying for more than 3 hours within 48 hours of vaccination, hypotonic-hyporesponsive episode, hypersensitivity to the vaccine, seizures with or without fever within 3 days - the child would be excluded from further vaccine dosing as a precautionary measure as those events might be attributed to the whole cell B. pertussis component ${ }^{38}$.

The primary objective of the trial was to assess the immune response to PRP-T when mixed with the locally manufactured DTPw from Instituto Butantan as compared to a mixture with DTPw from GSK Biologicals one month after the 3rd vaccine dose. Secondary objectives were the immune response to PRP-T after 2 doses as well as the immune response to all other vaccine antigens (diphtheria toxoid, tetanus toxoid, and Bordetella pertussis after 3 doses). Further secondary objectives were the safety and reactogenicity of the two vaccine combinations.

Safety and reactogenicity. Each child was observed for at least 15 min for immediate reactions after the injection of the DTPw/PRP-T vaccines. The parents/ guardians received diary cards and were instructed by the study nurses to document any local reactions (pain, redness, swelling), as well as systemic reactions (fever, irritability, drowsiness, feeding problems, unusual crying) including severity and duration of the event occurring from the day of vaccination through the next three days. In addition, parents were instructed to record any other unsolicited adverse event within 30 days post vaccination on the diary card.

Serology. Blood samples were taken prior to the first dose, two months after the 2nd dose, and one month after the $3 r d$ dose. Sera were stored at $-20^{\circ} \mathrm{C}$ until analyses were performed at GSK Biologicals central laboratories in Rixensart, Belgium in a blinded fashion.
Although anti-diphtheria and anti-tetanus titers > $0.01 \mathrm{IU} /$ $\mathrm{ml}$ are generally considered to be protective and ELISA results are in general well correlated with in-vivo neutralization tests ${ }^{29}$, this correlation is reduced at antibody titers $<0.1 \mathrm{IU} / \mathrm{ml}$. Thus, anti-diphtheria and antitetanus ELISA titers $>0.1 \mathrm{IU} / \mathrm{ml}$ are commonly set as a conservative cut-off. Samples with anti-diphtheria ELISA titers $<0.1 \mathrm{IU} / \mathrm{ml}$ were re- tested with a more sensitive invitro VERO cell neutralization assay ${ }^{31}$ with a cut-off at $0.016 \mathrm{IU} / \mathrm{ml}$. Bordetella pertussis antibodies were determined using a whole-cell based commercial ELISA kit with a cut-off at $15 \mathrm{EL} \mathrm{U/ml} \mathrm{(Labsystem,} \mathrm{ICN-Flow,}$ Helsinki, Finland). An ELISA assay was used to measure the antibodies against PRP with a cut-off at $0.15 \mathrm{Ug} / \mathrm{ml}$.

For all components, antibody levels above the cutoff were considered to be protective, except for Bordetella pertussis for which no serological correlate for protection has been established. A vaccine response to Bordetella pertussis was defined as the induction of antibody titers above the assay cut-off in initially seronegative subjects. In initially seropositive subjects a post-vaccination titer at least equal to the infant's prevaccination titer was required, taking into account the half-life of maternal antibodies, estimated at 40 days ${ }^{45}$.

Statistical methods. The statistical analyses were performed using SAS 6.12 on Windows NT and StatXact-3. The sample size of 51 infants evaluated per group was based on the primary objective to show noninferiority of the anti-PRP response when PRP-T was mixed with DTPw from Butantan compared to mixture with DTPw from GSK Biologicals ( $\mathrm{n}$ Query, two group test of equivalence in proportions; one-sided test, $\alpha=0.05, \beta=0.1$ ). A FDA and EMEA accepted method to show non-inferiority of two biological products is to agree a priory on a clinically acceptably difference between the two products, and then build $90 \%$ confidence limits around that difference. If the priory accepted difference falls within this interval, the two products are deemed to be equivalent for the parameter tested. The statistical hypothesis of non-inferiority of the PRP-T/DPTw Butantan mixture was thus tested by constructing confidence limits around the difference in anti-PRP seroprotection rates $>0.15 \mu \mathrm{g} / \mathrm{ml}$. If the lower $90 \%$ confidence limit of the difference was less than $10 \% 2$ vaccines combinations were deemed equivalent.

In addition, seropositivity rates as well as geometric mean titers (GMT) with their 95\% confidence intervals were calculated for all vaccine related antibodies prevaccination and post-III vaccination. Post III reverse cumulative distribution curves were produced for all active vaccine components.

For safety and reactogenicity, the percentage of subjects with adverse events was computed and 95\% confidence intervals were compared between groups, in addition to Fisher's exact test. Demographic comparability of the 2 groups was tested by Fisher's exact test for the male/female ratio and by ANOVA for age differences. 


\section{RESULTS}

A total of 108 subjects were enrolled into the study between May and July 1999. Of those, 54 infants were randomly allocated to the PRP-T/DTPw Butantan combination (group 1) and 54 to the PRP-T/DTPw GSK Biologicals vaccine (group 2). Group 1 consisted of 28 female and 26 male infants with a mean age of 8.8 (+1.4 SD) weeks at the time of the first dose. There was no difference in demographics compared to group 2 which included 32 females and 22 males being 8.7 (+1.6 SD) weeks of age at first vaccination.

Of the total cohort of 108 infants, 107 infants were included in the analysis for safety and reactogenicity (99.1\%). One child of group 2 had to be excluded after receiving a non-study vaccine.

For analysis of the immunogenicity, 2 cohorts of children were analyzed: an intent-to-treat cohort (ITT) where all subjects with paired blood samples were included ( $n=95: 45$ in group 1 and 50 in group 2), and an according-to-protocol cohort (ATP), including all infants with paired blood samples and compliance to vaccination/blood sampling timings ( $n=88: 41$ in group 1 and 47 in group 2). Reasons for the 20 dropouts from the ATP analysis: receipt of a non-study vaccine $(n=1)$, violation of in/exclusion criteria $(n=3)$, non-compliance with the vaccination schedule $(n=14)$ and noncompliance with the blood sampling schedule $(n=2)$. For 86 of these 88 subjects, blood samples were available from all 3 sampling time-points.

Serological response to PRP-T. The anti-PRP response of the 2 study groups is given in Table 1 . Both groups had comparable pre-vaccination GMT's of $0.24 \mu \mathrm{g} / \mathrm{ml}$ and $0.18 \mu \mathrm{g} / \mathrm{ml}$, respectively. After the second

Table 1 - Anti-PRP antibody response (ATP).

\begin{tabular}{|c|c|c|c|c|c|c|}
\hline \multirow[b]{2}{*}{ No. of samples } & \multicolumn{2}{|c|}{ Before first dose (age $=2 \mathrm{mo})$} & \multicolumn{2}{|c|}{ After second dose (age $=6 \mathrm{mo}$ ) } & \multicolumn{2}{|c|}{ After third dose $($ age $=7 \mathrm{mo})$} \\
\hline & Group $1(n=40)$ & Group $2(n=46)$ & Group $1(n=41)$ & Group $2(n=46)$ & Group $1(n=40)$ & Group $2(n=46)$ \\
\hline$\%$ and $95 \% \mathrm{Cl}$ with $\geq 0.15 \mu \mathrm{g} / \mathrm{ml}$ & $63(46 ; 77)$ & $48(33 ; 63)$ & $98(87 ; 100)$ & $100(92 ; 100)$ & $100(91 ; 100)$ & $100(92 ; 100)$ \\
\hline$\%$ and $95 \% \mathrm{Cl}$ with $\geq 1.0 \mu \mathrm{g} / \mathrm{ml}$ & $5(1 ; 17)$ & $7(1 ; 18)$ & $83(68 ; 93)$ & $89(76 ; 96)$ & $98(87 ; 100)$ & $96(85 ; 100)$ \\
\hline GMT and $95 \% \mathrm{Cl} \mu \mathrm{g} / \mathrm{ml}$ & $0.24(0.17 ; 0.33)$ & $0.18(0.13 ; 0.24)$ & $4.32(2.70 ; 6.92)$ & $4.73(3.14 ; 7.14)$ & $9.34(6.46 ; 13.51)$ & $10.25(7.09 ; 14.81)$ \\
\hline
\end{tabular}

Group 1: PRR-T mixed with DTPw Butantan

Group 2: PRR-T mixed with DTPw GSK Biologicals.

dose, $98 \%$ and $100 \%$ of infants had anti-PRP antibody titers $>0.15 \mu \mathrm{g} / \mathrm{ml}$, and after the third dose $100 \%$ children in both groups had titers above $0.15 \mu \mathrm{g} / \mathrm{ml}$. Because the sample size in neither group reached the required 51 subjects per group, the study lacked statistical power to refute inferiority of Group 1. The lower $90 \%$ confidence limit of the $0 \%$ difference between the two groups was $13 \%$ and thus marginally surpassing the pre-set limit of $10 \%$. GMTs after the third dose were very similar in the two study groups (9.34 and $10.25 \mu \mathrm{g} / \mathrm{ml}$ ) with widely overlapping confidence intervals. The comparable immune response of both groups to PRP is also shown by the reverse cumulative distribution curves for anti-PRP titers that are almost identical (Figure 1)
When analyzing the ITT cohort, the results were similar (data not shown). After 3 doses, $100 \%$ of children in both groups had titers $>0.15 \mu \mathrm{g} / \mathrm{ml}$. In this ITT analysis $98 \%$ of children in group 1 and $96 \%$ in group 2 had titers $>1.0 \mu \mathrm{g} / \mathrm{ml}$ with GMT's of $9.02 \mu \mathrm{g} / \mathrm{ml}$ and $10.36 \mu \mathrm{g} / \mathrm{ml}$, respectively.

Serological response to diphtheria, tetanus and pertussis. Seroprotection/vaccine response rates and GMTs for diphtheria, tetanus and Bordetella pertussis are shown in Table 2. For diphtheria, pre-vaccination seropositivity rates and GMT's were within the same range in the two groups. After 3 doses, $88 \%$ of infants in group 1 compared to $98 \%$ of infants in group 2 had ELISA diphtheria antibody levels $>0.1 \mathrm{lU} / \mathrm{ml}$. Anti-diphtheria

Table 2 - Anti-diphtheria, anti-tetanus and anti-Bordetella pertussis antibody response - ATP cohort.

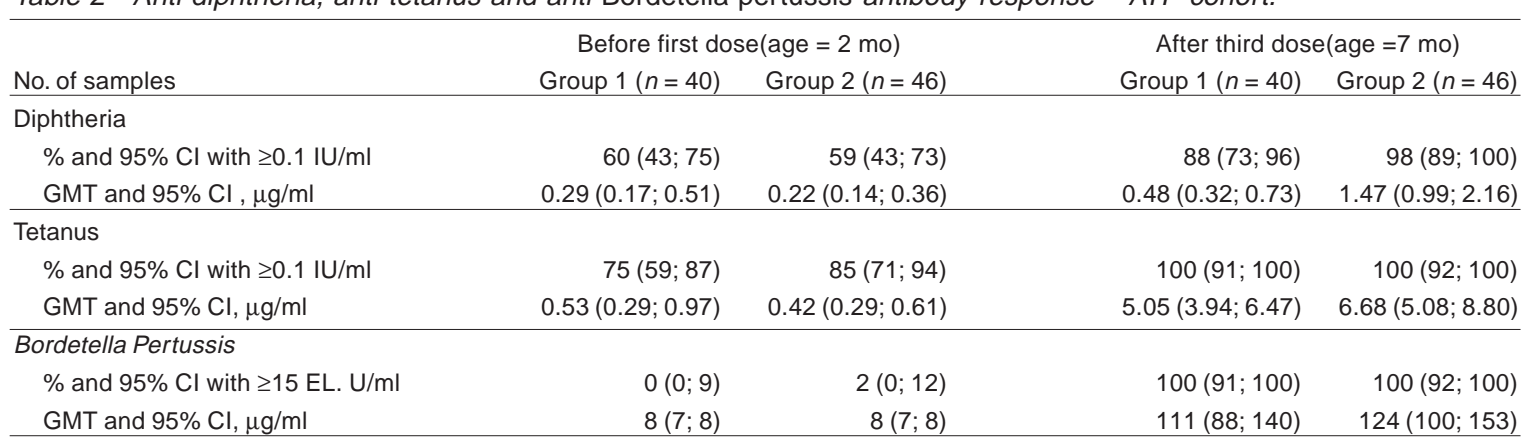

Group 1: PRR-T mixed with DTPw Butantan

Group 2: PRR-T mixed with DTPw GSK Biologicals 


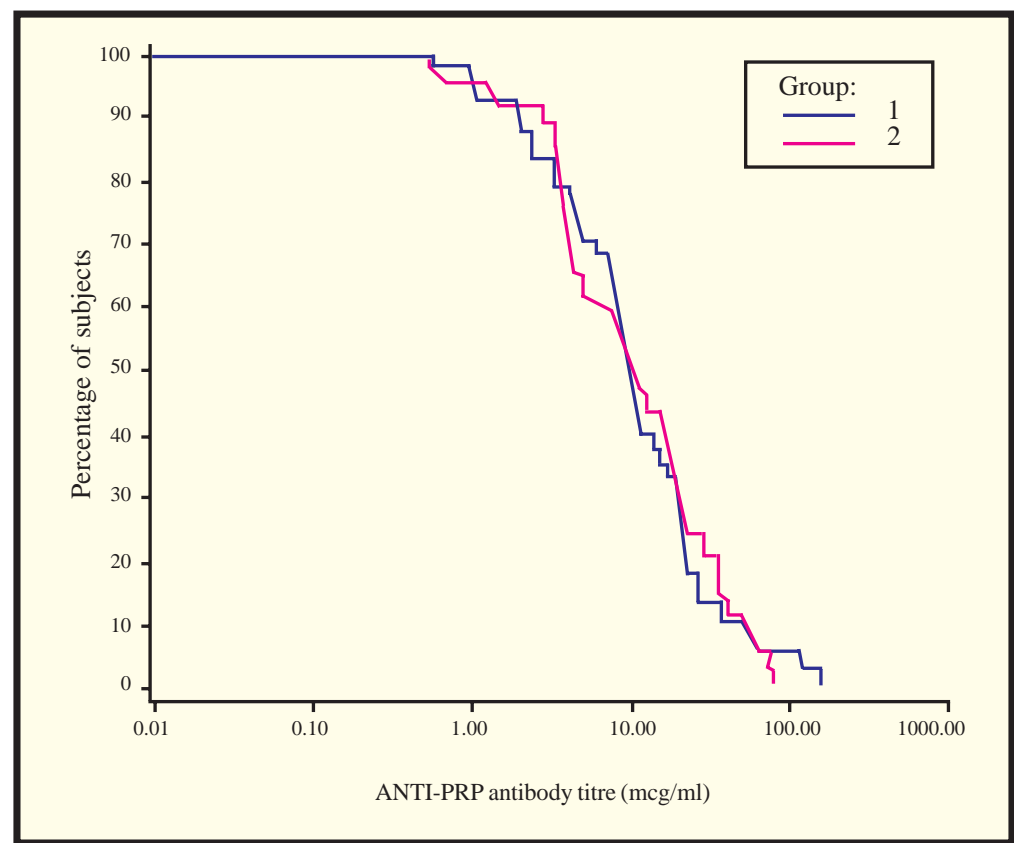

Notes: Group 1:Local DTPw/ GSK's Hib ${ }_{10}$

Group 2: GSK's DTPw/GSK's Hiberix ${ }^{T M}$

Figure 1 - Reverse cumulative distribution curves for anti-PRP (PIII): ATP cohort for immunogenicity analysis.

GMTs were significantly higher in group 2 than in group $1(1.47 \mathrm{IU} / \mathrm{ml}$ vs. $0.48 \mathrm{IU} / \mathrm{ml})$ and the reverse cumulative distribution curves for anti-diphtheria titers showed a clear right shift towards higher titers in group 2 (Figure 2).

Results in the ITT cohort were similar with $87 \%$ of infants in group 1 and $98 \%$ of infants in group 2 showing titers $\geq 0.1 \mathrm{IU} / \mathrm{ml}$ (data not shown).

In order to determine the true rate of unprotected infants against diphtheria, a more sensitive VERO cell neutralization assay was performed in all ELISA negative samples. After 3 doses of vaccine $5 / 40$ subjects in group 1 and 1/46 subjects in group 2 were anti-diphtheria negative by ELISA. Upon re-testing by VERO cell test 4/ 5 ELISA negatives in group 1 tested positive with one true vaccine failure, and the single ELISA negative subject in group 2 tested positive by VERO assay as well. Thus, the true anti-diphtheria protection rate in group 1 was $98 \%(95 \% \mathrm{Cl}: 85 ; 100)$ and $100 \%$ in group 2 (95\% Cl: 85 ; 100) with significantly higher GMTs in group 2.

For tetanus, all infants in both groups had protective anti-tetanus levels after 3 doses of vaccine (Table 2). GMTs and reverse cumulative distribution curves for antitetanus were similar (Figure 3).

No significant differences in response to pertussis between the 2 groups were noted after the third dose. Following 3 doses of either vaccine combination, all infants in both groups were seropositive with similar
GMTs of 111 and $124 \mathrm{EL} \mathrm{U} / \mathrm{ml}$. The reverse cumulative distribution curves for anti-Bordetella pertussis closely overlapped (Figure 4).

Safety and reactogenicity. The safety analysis was performed as intent to treat and based on a total of 107 subjects who received at least one dose of study vaccine (54 in group 1 and 53 in group 2). In group 1, 47 children received all 3 doses, 4 received 2 doses and 3 children got 1 dose of vaccine, for a total of 152 doses. In group 2,51 infants got all 3 doses and one child each received 2 doses and 1 dose for a total 156 doses. A total of 145/ 152 doses in group 1 and 152/156 doses in group 2 could be evaluated for safety and reactogenicity.

Table 3 shows the incidences and severity of local and systemic reactions during the four-day follow-up period. Local and systemic reactions were common in both groups, but most reactions were mild and resolved spontaneously within the observation period. There was no statistical difference between the groups except for severe pain and irritability, using Fisher's exact test at 0.05 significance level without adjusting for multiple testing. Neither local nor systemic reactions increased with doses in either of the two study groups (data not shown). Among the systemic reactions, fever $\leq 37.5^{\circ} \mathrm{C}$ was the most common event occurring after $39 \%$ of doses in group 1 and after $45 \%$ of doses in group 2 . However, fever $\geq 39^{\circ} \mathrm{C}$ occurred only in $1 \%$ and $4 \%$ of doses, respectively. There was no case of hypotonic- 


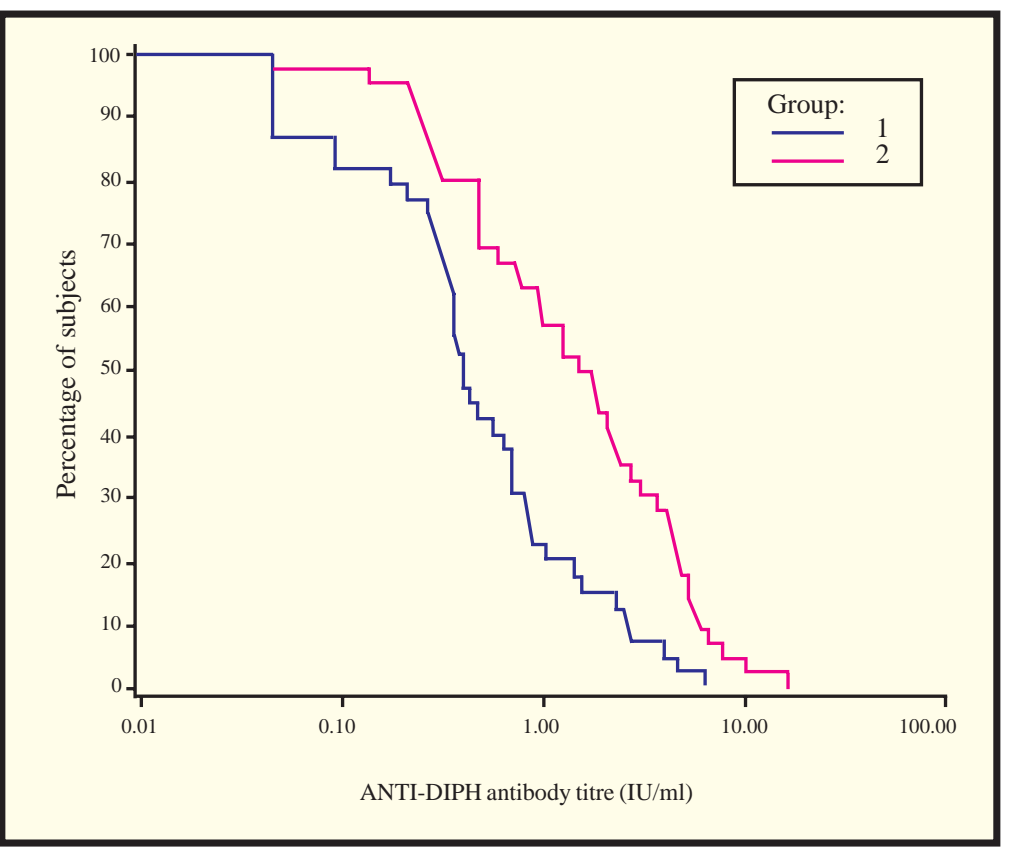

Notes: Group 1:Local DTPw/ GSK's Hib

Group 2: GSK's DTPw/GSK's Hiberix ${ }^{\mathrm{TM}}$

Figure 2 - Reverse cumulative distribution curves for anti-diphtheria(PIII): ATP cohort for immunogenicity analysis.

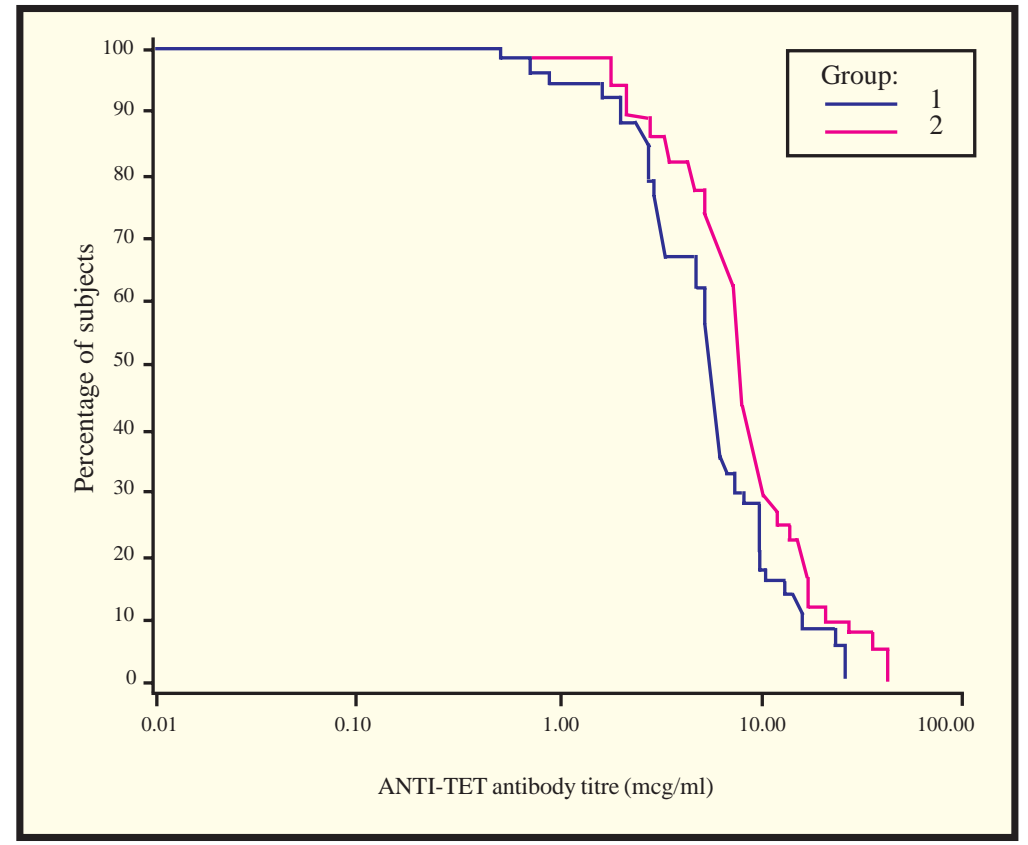

Notes: Group 1 :Local DTPw/ GSK's Hib

Group 2: GSK's DTPw/GSK's Hiberix ${ }^{\mathrm{TM}}$

Figure 3 - Reverse cumulative distribution curves for anti-tetanus(PIII): ATP cohort for immunogenicity analysis. 


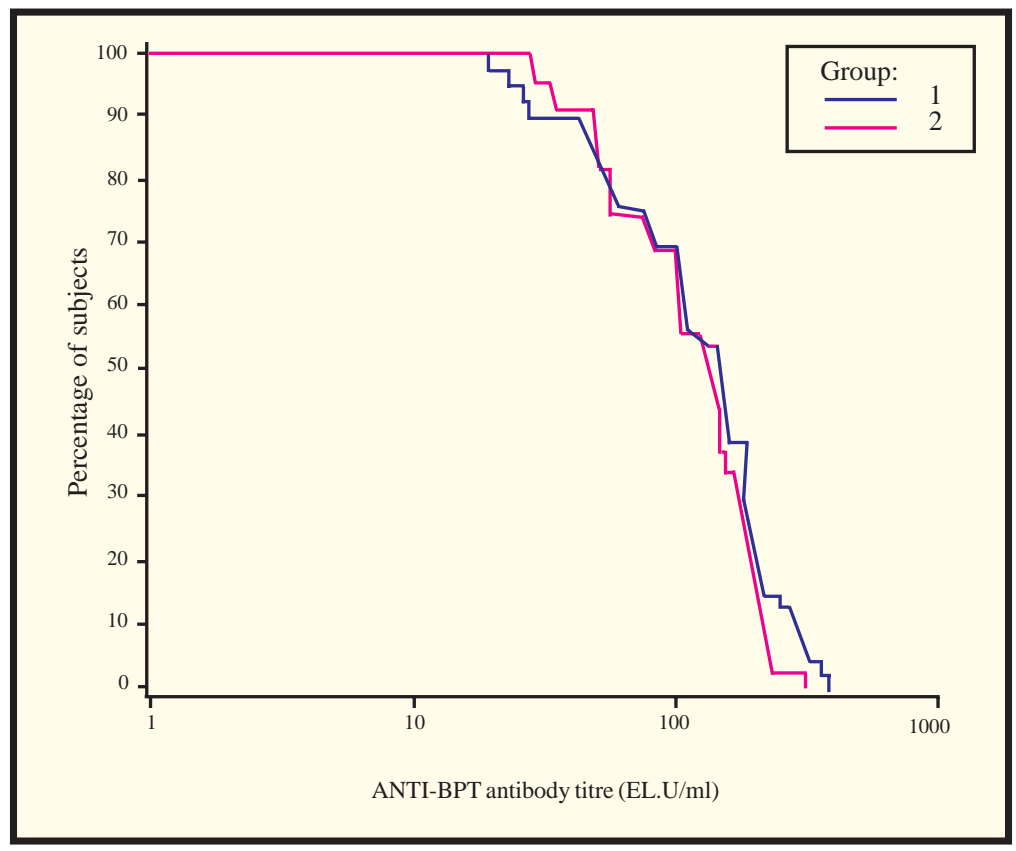

Notes: Group 1:Local DTPw/ GSK's Hib

Group 2: GSK's DTPw/GSK's Hiberix ${ }^{\mathrm{TM}}$

Figure 4 - Reverse cumulative distribution curves for anti-Bordetella Pertussis (PIII): ATP cohort for immunogenicity analysis.

Table 3 - Severity of local and systemic reactions per dose during 4-day follow-up period. (\% and 95\% C.I.)

\begin{tabular}{lrr}
\hline & Group 1 & Group 2 \\
Number of doses & $n=145$ & $n=152$ \\
\hline \% with pain & $36(28 ; 44)$ & $45(37 ; 53)$ \\
- grade 3 & $7(3 ; 12)$ & $15(10 ; 22)$ \\
\% with redness & $34(26 ; 42)$ & $37(29 ; 45)$ \\
- grade 3 & $2(0 ; 6)$ & $1(0: 4)$ \\
\% with swelling & $28(21 ; 36)$ & $33(26 ; 41)$ \\
- grade 3 & $3(1 ; 8)$ & $1(0 ; 5)$ \\
\% with fever ${ }^{3} 37.5^{\circ}$ C & $39(31 ; 47)$ & $45(37 ; 54)$ \\
- fever $339^{\circ}$ C & $1(0 ; 4)$ & $4(2 ; 8)$ \\
\% with irritability & $34(26 ; 42)$ & $43(35 ; 51)$ \\
- grade 3 & $1(0 ; 4)$ & $5(2 ; 10)$ \\
\% with loss of appetite & $9(5 ; 15)$ & $15(9 ; 21)$ \\
- grade 3 & $0(0 ; 3)$ & $3(1 ; 8)$ \\
\% with drowsiness & $21(14 ; 28)$ & $15(10 ; 22)$ \\
- grade 3 & $0(0 ; 3)$ & $2(0 ; 6)$ \\
\hline
\end{tabular}

Group 1: PRP-T with DTPw Butantan

Group 2: PRP-T with DTPw GSK Biologicals

$P=0.05$

hyporesponsive reactions, seizures, other neurological sequelae or allergic reactions in either group. In 2 infants of each group, additional unsolicited events were reported during the 5-month study period, all being typical childhood infections and judged by the investigator as unrelated to vaccination. One child of group 1 was hospitalized with respiratory distress and spasmodic coughing 8 weeks after the second vaccination. The child recovered under treatment without sequelae.

\section{DISCUSSION}

The feasibility to reconstitute lyophilized PRP-T with DTPw or DTPw-HB has been validated, and various DTPw/PRP-T and DTPw-HB/PRP-T combined vaccines are already registered in many countries ${ }^{13283344}$. However, any new combination of differently sourced vaccine components has to be tested again for its immunogenicity and safety profile and has to be registered before use. Recently, the Brazilian vaccine manufacturer BioManguinhos / FIOCRUZ acquired from GSK Biologicals the technology for production of a PRP-T vaccine. After showing bioequivalence to the GSK Biologicals vaccine the Bio-Manguinhos / FIOCRUZ PRP-T vaccine has been licensed in Brazil and is now universally used for the Hib vaccination by the Brazilian Ministry of Health $(\mathrm{MOH})$. In the present study, Hib PRP-T vaccine produced with the common technology of GSK Biologicals and BioManguinhos / FIOCRUZ technology was reconstituted either with a DTPw vaccine produced by Butantan or with a DTPw produced by GSK Biologicals which is a licensed combination in many countries worldwide.

Although due to a limited statistical power noninferiority of the PRP-T/DTPw Butantan combination 
could not be excluded, the study shows that the immune response to PRP-T after 3 doses of vaccine was very similar between the PRP-T/ DTPw Butantan and GSK Biologicals combination. All children in both groups had antibody titers $\geq 0.15 \mu \mathrm{g} / \mathrm{ml}$ following a full vaccination course. There was also no difference in the percentage of children with titers $\geq 1.0 \mu \mathrm{g} / \mathrm{ml}(97.5 \%$ and $95.7 \%)$ nor in the GMTs $(9.3 \%$ and $10.2 \mu \mathrm{g} / \mathrm{ml}$ ). The anti-PRP protection rates and GMTs achieved with both DTPw/PRP-T combinations in this study are well in-line with results from different DTPw/PRP-T combination trials performed in various Latin American and Asian countries ${ }^{79141539}$.

An interesting finding in some of those studies was a substantially higher anti-PRP immune response among infants in Latin America, compared to infants of similar age from the USA and Europe 18202325 . The reason for these differences in the anti-PRP response in different geographic areas of the world is not clear. An explanation offered is antigenic stimulation by crossreacting enteric bacteria. For example, biologically active anti-PRP antibodies can be induced by colonization with E. coli K-100, and other enteric bacteria, and also Staphylococcus aureus ${ }^{23} 42$. It is possible that children living in crowded conditions are more often exposed to these cross-reacting bacteria. Another observation is the association of high anti-PRP titers with an increased number of household members, indicating that the higher responses may be attributed to increased exposure to the Hib organism transmitted by siblings ${ }^{25}$.

One important observation in this study was that already after 2 vaccine doses $97.6 \%$ and $100 \%$ of infants, respectively, had anti-PRP titers greater than $0.15 \mu \mathrm{g} / \mathrm{ml}$, the antibody level which conservatively indicates protection ${ }^{13} .82 .9 \%$ of children in the PRP-T/ DTPw Butantan and $89.1 \%$ in the PRP-T/DTPw GSK Biologicals group had even titers $\geq 1.0 \mu \mathrm{g} / \mathrm{ml}$ with GMTs of 4.3 and $4.7 \mu \mathrm{g} / \mathrm{ml}$ after 2 doses only. These results are to be put in context with the early Hib vaccine efficacy trials in Finland, where after 3 doses of PRP-D $58 \%$ of children had titers above $0.15 \mu \mathrm{g} / \mathrm{ml}$ and only $29 \%$ had titers greater than $1.0 \mu \mathrm{g} / \mathrm{ml}$, yet the protective efficacy against invasive Hib disease was far above $95 \% 636$

The finding that practically all infants had protective anti-PRP antibody levels already after 2 doses of either DTPw/PRP-T combination is of special importance from a public health point of view. The reason for combining PRP-T with a well-established vaccine such as DTPw is to facilitate the introduction of Hib vaccine into the EPI vaccination program in Brazil. In 1998, the nationwide coverage for 3 doses of DTPw was $93 \%$ in Brazil. However, there were still regions with coverage rates as low as $70 \%{ }^{29}$. Because of the high immunogenicity of PRP-T in combination with DTPw in both combinations tested, even those with low compliance would have been protected against Hib after having received 2 doses only of the DTPw/PRP-T vaccine. The other important public health benefit of those DTPw/PRP-T combinations is an earlier Hib protection already after 2 doses at 4-5 months due to the improved kinetics. This is clinically relevant as about $20-50 \%$ of Hib disease in Brazil and other tropical countries occurs before 6 months of age 213436 .

A remarkable difference between the two DTPw/PRP-T combinations tested was the lower anti-diphtheria response in the Butantan combination which has a D component with lower potency. In this feasibility trial and with the batch used, the anti-D titers were not only lower than the titers in the GSK Biologicals combination, but also compared to Dresponses in other DTPw/ Hib combinations ${ }^{1} 103344$. Thus reinforcing the need for all infants to receive a DTPw booster in the $2^{\text {nd }}$ year of life as recommended by the Brazilian $\mathrm{MOH}$, especially as diphtheria is still present in Brazil with over 50 confirmed cases in $1999^{5}$. In addition, there are good reasons that a further $\mathrm{D}$ booster with reduced potency should be given to adolescents or young adults, either as Td as currently recommended by the National Immunisation Program, or in the future the recently licensed DTP acellular pertussis vaccine.

With regard to anti-tetanus antibodies, the results of the two DTPw/PRP-T preparations were similar. All children had high protective antibody titers after 3 doses. Of interest is the finding that before vaccination at 2 months of age, over $75 \%$ of infants had maternal antitetanus antibodies, indicating that the recommendation of tetanus vaccination in pregnancy to avoid neonatal tetanus is well respected in Brazil. Since the magnitude of the anti-PRP antibody response may be influenced by immunological priming to the carrier protein ${ }^{2} 3819$, tetanus toxoid, we compared the anti-PRP response after 2 and 3 doses in infants with and without antitetanus antibodies at study entry. There was no difference in the anti-PRP response whether or not infants had maternal anti-tetanus antibodies.

With regard to pertussis, both vaccines elicited a similar anti-Bordetella pertussis response. However, it is to be kept in mind that anti-Bordetella pertussis antibodies are not a surrogate marker of protection but only for vaccine response. The GSK Biologicals DTPw is one of the few whole-cell pertussis vaccines which have been tested for protective efficacy in a prospective clinical trial showing an efficacy of $97 \%$ in the prevention of typical pertussis ${ }^{41}$. Of interest is that only $1 / 106$ infants in the study had maternal antipertussis antibodies at 2 months of age. Typically, at this age, $10-20 \%$ of infants have maternal antibodies ${ }^{1812}$. Thus indicates that most of the mothers in this study do not have antibodies. This is potentially dangerous because these mothers may serve as a reservoir and transmit pertussis to their newborn infants. Therefore, a booster with DTPa in adolescents and young adults should be considered which not only boosts pertussis protection in those age groups, but which also indirectly would protect infants until they possess their own vaccine induced pertussis immunity.

Local and systemic reactions were common in both groups, but the incidence was similar to what is seen 
when DTPw vaccines are given alone ${ }^{1022}$. In addition, virtually all events were not severe and resolved spontaneously. There was a trend towards lower incidences of solicited events in the group receiving PRP-T/DTPw Butantan, most likely reflecting the lower diphtheria potency of this vaccine, as the $\mathrm{D}$ content is known to be associated with local and systemic reactions.

In summary, the present feasibility study shows that the PRP-T produced with the GSK Biologicals/BioManguinhos technology can be mixed with the DTPw from Butantan. This DTPw/Hib combination is safe and highly immunogenic for the Hib response already after 2 doses, as well as for tetanus and pertussis. The lower anti-diphtheria titers can probably be overcome by a DTPw booster in the second year of life and Tdpa boosters later in life. If a confirmatory trial reveals similar results on this feasibility study, this new DTPw/Hib combination will not only help decrease the number of injections and thus costs, but will also improve compliance and thereby enhance the uptake of routine Hib vaccination in Brazil.

\section{REFERENCES}

1. Amir J, Melamed R, Bader J, Ethevenaux C, Fritzell B, Cartier JR, Armingnon F, Dagan R. Immunogenicity and safety of a liquid combination of DT-PRP-T versus lyophilized PRP-T reconstituted with DTP. Vaccine 15: 149-154, 1997.

2. Barrington T, Gyhrs A, Kristensen K, Heilmann C. Opposite effects of actively and passively acquired immunity to the carrier on response of human infants to a Haemophilus influenza type $b$ conjugate vaccine. Infections Immunology 62: 9-14, 1994.

3. Bell F, Martin A, Blondeau C, Thornton C, Chapois J, Finn A. A combined diphtheria, tetanus, pertussis, and Haemophilus influenza type $b$ vaccine for primary immunisation. Archives of Diseases of Childhood 75: 298-303, 1996.

4. Booy R, Aitken SJ, Taylor S, Tudor-Williams. Immunogenicity of combined diphtheria, tetanus, and pertussis vaccine given at 2 , 3 , and 4 months versus 3,5 , and 9 months of age. Lancet 339 : 507-510, 1992.

5. Bryan JP, Silva HR, Tavares A, Rocha H, Scheld WM. Etiology and mortality of bacterial meningitis in northeastern Brazil. Review in Infectious Diseases 12: 128-135, 1990.

6. Campbell H, Carter H. Rational use of Haemophilus influenza type b vaccine. Drugs 46: 378-383, 1993.

7. Febres OC, Decker M, Estopian M, Bordones G, Edwards KM. Enhanced antibody response in Venezuelan infants immunised with Haemophilus influenza type $\mathrm{b}$ - tetanus toxoid conjugate vaccine. Pediatric Disease Journal 13: 635-639, 1994.

8. Chotpitayasunondh T, Panpitoat C, Thisyakorn U, Furer E, Que Ju, Haster T, Crysz SJ. Safety and immunogenicity of a Haemophilus influenza type b polysaccharide - tetanus toxoid conjugate vaccine combined with diphtheria, tetanus and pertussis vaccine in thai infants. Southeast Asian Journal of Tropical Medicine and Public Health 28: 91-98, 1997.

9. Clemens JD, Ferreccio C, levine MM, Horwitz I, Rao MR, Edwards, KM, Fritzell B. Impact of Haemophilus influenza type b polysaccharide-tetanus protein conjugate vaccine on response to concurrently administered diphtheria-tetanus-pertussis vaccine. Journal of the American Medical Association 267: 673678, 1992.

10. Cody CL, Barraff LJ, Cherry JD, Marcy SM, Manclark CR. Nature and rates of adverse reactions associated with DTP and DT immunisations in infants and children. Pediatrics 68: 650-660, 1981.

11. Dagan R, Botujansky C, Watemberg N, Arbelli Y, Belmaker I, Ethevenaux C, Fritzell B. Safety and immunogenicity in young infants of Haemophilus b-tetanus protein conjugate vaccine, mixed in the same syrinhe with diphtheria-tetanus-pertussis- enhanced poliovirus vaccine. Pediatrics Infectious Disease Journal 13: 356-362, 1994.

12. Diez-Delgado J, Dal-Re R, Llorente M, Gonzalez A, Lopez J. Hepatitis B componet does not interfere with the immune response to diphtheria, tetanus, and whole-cell Bordetella pertussis components of a quadrivalent (DTPw-HB) vaccine: a controlled trial in healthy infants. Vaccine 15: 1418-1422, 1997.

13. Eskola J, Kaethy $\mathrm{H}$. Early immunisation with conjugate vaccines. Vaccine 15: 1433-1438, 1998.

14. Fernandez J, Balter S, Feris J, Gomez E, Garib Z, Castellanos PL, Sanchez J, Romero-Steiner S, Levine OS. The immunogenicity of fractional-dose regimens of PRP-T of Haemophilus influenzae type B vaccination (Abstract 1400). In: $39^{\text {th }}$ ICAAC - Interscience Conference on Antimicrobial Agents and Chemotherapy San Francisco, USA, 26-29, 1999.

15. Ferrecio C, Clemans J, Avendano A, Horwitz I, Flores C, Avila L, Cayazzo M, Fritzell B, Cadoz M, Levine M. The clinical and immunological response of chilean infants to Haemophilus influenzae type $\mathrm{b}$ polysaccharide-tetanus protein conjugate vaccine coadministered in the same syringe with DiphtheriaTetunus toxoids pertussis vaccine at two, four and six months of age. Pediatric Infectious Disease Journal 10: 764-771, 1991.

16. Gold R, Scheifele D, Barreto L, Wiltsey S, Bjornsen G, Meekison W, Guasparini R, Medd L. Safety and immunogenicity of Haemophilus influenzae vaccine (tetanus toxoid conjugate) administered concurrently with Diphteria and tetanus toxoids, pertussis vaccine and inactivated poliomyelitis vaccine to healthy infants at two, four and six months of age. Pediatric Infectious Disease Journal 13: 348-355, 1994.

17. Goldblatt D. Conjugate vaccines. Clinical and Experimental Immunology 119: 1-3, 2000.

18. Granoff DM, Anderson EL, Osterholm MT, Holmes SJ, mcHugh JE, Belshe RB, Medley F, Murphy TV. Differences in the immunogenicity of three Heamophilus influenzae type b conjugate vaccines in infants. Journal of Pediatrics 121: 187-194, 1992.

19. Granoff DM, Holmes SJ, Belshe RB, Osterholm MT, McHugh JE, Anderson EL. Effect of carrier proming on atibiody response to Haemophilus influenza type b conjugate vaccines in infants. Journal of the American Medical Association 272: 1116-1121, 1994.

20. Greenberg DP, Vadheim CM, Partridge S, Chang SJ, Chiu CY, Ward JI. Immunogenicity of Haemophilus influenza type $b$ tetanus toxoid conjugate vaccine in young infants. The Kaiser-UCLA study group. Journal of Infectious Disease 170: 76-81, 1994.

21. Grinbaum RS, Mendonça JS, Almeida ALSL. Epidemiology of Haemophilus influenza in São Paulo, Brazil, and implications for 
future routine immunisations (Abstract 103.010). In: $7^{\text {th }}$ International Congress for Infectious Diseases, Hong Kong, June 10-13, 1996.

22. Gustafsson L, Hallander HO, Olin P, Reizenstein E, Storsaeter J. A controlled trial of a two-component acellular, a five-component acellular, and a whole-cell pertussis vaccine. New England Journal of Medicine 334: 349-355, 1996.

23. Hoppenbrouwers K, Lagos R, Swennen B, Ethevenaux C, Knops J, Levine MM, Desmyter J. Safety and immunogenicity of an Haemophilus influenza type $b$ - tetanus toxoid conjugate (PRPT) and diphtheria-tetanus-pertussis (DTP) combination vaccine administered in a dual-chamber syringe to infants in Belgium and Chile. Vaccine 16: 921-927, 1998.

24. Lagos R, Horwitz I, Toro J, San Martin O, Abrego O, Bustamante C, Wasserman SS, Levine OS, Levine MM. Large scale, postlicensure, selective vaccination of chilean infants with PRPT conjugate vaccine: practicality and effectiveness in preventing invasive Haemophilus influenza type b infections. Pediatric Infection Disease Journal 15: 216-222, 1996.

25. Levine OS, Granoff DM, Lagos R, Fritzell B, Levine M. Factors associated with superior antibody response toa single dose of Haemophilus influenzae type b-tetanus toxoid conjugate vaccine administered to chilean infants at 2 months of age. Vaccine 15: 325-328, 1997.

26. Macaluso A, Pivetta S, Maggi RS, Tamburlini G, Cattaneo A. Dexamethasone adjunctive theraphy for bacterial meningitis in children: a retrospective study in Brazil. Annals of Tropical Pediatrics 16: 193-198, 1996.

27. Melville-Smith ME, Balfour E. Estimation of Corynebacterium diphtheriae antitoxin in human sera: a comparison of enzymelinked immunosorbent assay with the toxin neutralisation test. Journal of Medical Microbiology 25: 279-283, 1988.

28. Miller MA, Meschievitz CK, Ballango GA, Daum RS. Safety and immunogenicity of PRP-T combined with DTP: excretion of capsular polysaccharide and antibody response in the immediate post-vaccination period Pediatrics 95: 522-527, 1995.

29. Ministério da Saúde. Boletim epidemiologico on line. www.saude.gov.br/inform, 1998.

30. Ministério da Saúde. Boletim epidemiologico on line. www.saude.gov.br/inform, 1999.

31. Miyamura K, Nisho S, Ito A, Murato R, Kono R. Micro cell culture method for determination of diphtheria toxin and antitoxin titres using Vero cells:comparasion with rabbit skin method and practical application for sero-epidemiological studies. Journal of Biological Standardisation 2: 203-209, 1974.

32. Mulholland K, Hilton S, Adegabola R, Usen S, Oparaugo A, Omosigho C, Weber M, Palmer A, Schneider G, Jobe K, Lahai G, Jaffar S, Secka O, Lin K, Ethevenaux C, Greenwood B. Randomised trial of Haemophilus influenza type-b tetatus protein conjugate for prevention of pneumonia and meningitis in gambian infants. Lancet 349: 1191-1197, 1997.

33. Nolan TM, Hogg G, Darcy MA, Varigas J, McEwan J. Primary course immunogenicity and reactogenicity of a new DTPW (diphtheria-tetanus-whole cell pertussis) vaccine. Journal of Paediatrics Child Health 33: 413-417, 1997.

34. Peltola $\mathrm{H}$. Haemophilus influenzae type $\mathrm{b}$ disease and vaccination in Latin America and the Caribbean. Pediatric Infectious Disease Journal 16: 750-757, 1997.

35. Peltola H. Worldwide Haemophilus influenza type b disease at the beginning of the 21 st century: global analysis of the disease burden 25 years after the use of the polysaccharide vaccine and a decade after the advent of conjugates. Clinical Microbiological Review 13: 302-317, 2000.
36. Peltola $\mathrm{H}$, Kaethy $\mathrm{H}$, Virtanen $\mathrm{m}$, Maekelae $\mathrm{PH}$. Prevention of Haemophilus influenza type b bacteremic infections with the capsular polysaccharide vaccine. New England Journal of Medicine 310: 1561-1566, 1984.

37. Petre J. The design of DTP-based combined vaccines. In: $2^{\text {nd }}$ World Congress of Pediatric Infectious Diseases, Manila, Philippines, p. 74, 1999

38. Recommendations of the Advisory committee on Immunisation Practices (ACIP). Update on vaccine side effects, adverse reactions, contraindications, and precautions. Morbidity and Mortality Weekly Report 45: 1-35, 1996.

39. Richie E, Punjabi NH, Harjanto SJ, Wangsasaputral F, Sukandar M, Supriatman M, Simanjuntak $\mathrm{CH}$, Que Ku, Cryz SJJr. Safety and immunogenicity of combined diphtheria-tetanus-pertusis (whole cell and acellular) - Haemophilus influenzae-b conjugate vaccines administered to indonesian children. Vaccine 171: 1384-1393, 1999.

40. Santosham M, Reid R, Ambrosino DM, Wolff MC, Almeido-Hill J, Priehs C, Aspery KM, Garret S, Croll L, Foster S. Prevention of Haemophilus influenza type b infections in high-risk infants treated with bacterial polysaccharide immune globulin. New England Journal of Medicine 317: 923-929, 1987.

41. Scmitt HJ, Von Konig CH, Neiss A, Bogaerts H, Bock HL, SchulteWissermann H, Gahr M, Schult R, Folkens JU, Rauh W, Clemens $R$. Efficacy of acellular pertussis vaccine in early childhood after household exposure. Journal of the American Medical Association 275: 37-41, 1996

42. Schneerson R, Robbins JB. Induction of serum Haemophilus influenza type b capsular antibodies in adult volunteers fed crossreacting Escherichi Coli 075:K100:H5. New England Journal of Medicine 292: 1093-1096, 1975.

43. Shapiro ED. New vaccines against Haemophilus influenzae type b. Pediatrics Clinics of North America 37: 567-583, 1990.

44. Usonis V, Bakasenas V, Willems P, Bock H. Evaluation of the immunogenicity and reactogenicity of a new combined diphtheria, tetanus, whole-cell Bordetella pertussis and hepatitis B and Haemophilus influenzae type b (DTPw-HBV/Hib) vaccine in children at 3, 4, 5, and 6 months of age. Acta Medica Lituanica 6: 187-191, 1999.

45. Van Savage J, Decker M, Edwards KM, Sell SH, Karzon DT. Natural History of pertussis antibody in the infant and the effect on vaccine response. Journal of Infectious Disease 161: 487-492, 1990.

46. Ward J, Brenneman G, Letson GW, Heyward WL. Limmited efficacy of a Haemophilus influenzae type b conjugate vaccine in Alaska native infants. New England Journal of Medicine 323: 1393-1401, 1990.

47. Ward J, Zangwill KM. Haemophilus influenzae vaccines. In: Plotkin SA, Orenstein W (eds) Vaccines, Philadelphia: W.B. Saunders, p. 183-222, 1999.

48. World Health Organization. The children's vaccine initiative and the global programme for vaccines and immunisation recommendations form the special advisory group of experts, part 1. Weekly Epidemiological Record 71: 261-268, 1996.

49. World Health Organization. Global programme for vaccines and immunisation (GPV) - the WHO position paper on Heamophilus influenzae type b conjugate vaccines; Weekly Epidemiological Records 73: 64-68, 1998. 